IZA DP No. 6997

Cognitive Skills, Gender and Risk Preferences

Alison L. Booth

Pamela Katic

November 2012 


\title{
Cognitive Skills, Gender and Risk Preferences
}

\author{
Alison L. Booth \\ Australian National University, \\ University of Essex and IZA \\ Pamela Katic \\ Australian National University
}

\section{Discussion Paper No. 6997 \\ November 2012}

\author{
IZA \\ P.O. Box 7240 \\ 53072 Bonn \\ Germany \\ Phone: +49-228-3894-0 \\ Fax: +49-228-3894-180 \\ E-mail: iza@iza.org
}

Any opinions expressed here are those of the author(s) and not those of IZA. Research published in this series may include views on policy, but the institute itself takes no institutional policy positions. The IZA research network is committed to the IZA Guiding Principles of Research Integrity.

The Institute for the Study of Labor (IZA) in Bonn is a local and virtual international research center and a place of communication between science, politics and business. IZA is an independent nonprofit organization supported by Deutsche Post Foundation. The center is associated with the University of Bonn and offers a stimulating research environment through its international network, workshops and conferences, data service, project support, research visits and doctoral program. IZA engages in (i) original and internationally competitive research in all fields of labor economics, (ii) development of policy concepts, and (iii) dissemination of research results and concepts to the interested public.

IZA Discussion Papers often represent preliminary work and are circulated to encourage discussion. Citation of such a paper should account for its provisional character. A revised version may be available directly from the author. 
IZA Discussion Paper No. 6997

November 2012

\section{ABSTRACT}

\section{Cognitive Skills, Gender and Risk Preferences}

In this paper we utilise data from a unique new birth-cohort study to see how the risk preferences of young people are affected by cognitive skills and gender. We find that cognitive ability (measured by the percentile ranking for university entrance at age 18) has no effect on risk preferences measured at age 20. This is in contrast to experimental studies that use IQ measures to proxy cognitive skills. However we do find that gender matters. While young women are significantly more likely than young men to assess themselves as being prepared to take risks, women choose to invest significantly less when they are confronted with a clearly specified investment decision based on hypothetical lottery winnings. This difference between the impact of gender on risk attitudes and the hypothetical lottery investment suggests that impatience and framing affect young women and men differently.

JEL Classification: D01, D80, J16, J24

Keywords: cognitive ability, risk preferences, risk attitudes, gender

Corresponding author:

Alison L. Booth

Research School of Economics

College of Business and Economics

HW Arndt Building 25a

Australian National University

ACT 0200

Australia

E-mail: alison.booth@anu.edu.au

\footnotetext{
*We are grateful to the Australian Research Council for financial support. Our data come from the Youth in Focus Project. This is jointly funded by the Australian Government Department of Education, Employment and Workplace Relations, the Australian Government Department of Families, Housing, Community Services and Indigenous Affairs, Centrelink and the Australian Research Council (Grant Number LP0347164) and is carried out by the Australian National University. The findings and views reported in this paper are those of the authors and should not be attributed to any of these institutions. We thank Tue Gorgens and Chris Ryan for helpful advice about the data.
} 


\section{Introduction}

It is increasingly recognised that individual differences in risk aversion may contribute to explaining observed disparities in economic outcomes. For example, where remuneration in high-paying jobs is linked to bonuses based on a company's performance, individuals who are more risk averse than others may choose not to take such jobs because of the uncertainty. Differences in risk attitudes may also affect individual choices about seeking performance feedback or entering a competitive environment. This has been recognised in work charting gender differences in risky choices, as summarised by Eckel and Grossman (2008) for example.

But does cognitive ability also affect people's liking for risk? According to several recent studies, the answer is yes. If so, higher cognitive skills are likely to affect individual's economic outcomes indirectly through greater risk-taking behaviour, as well as through the more direct influence of cognitive ability on earnings.

Burks, Carpenter, Goette and Rustichini (2009) suggest that differences in perception of risky options due to cognitive ability may systematically affect individuals' choices. The more complex is an option, the larger the noise. If people of high cognitive skills perceive a complex option more precisely than people with low cognitive skills, they will be more likely to choose riskier options. Using a sample of 1,000 trainee truckers in the US, Burks et al (2009) found that lower cognitive ability - as measured by a nonverbal IQ test involving Raven's matrices - is associated with greater risk aversion and more pronounced impatience. ${ }^{1}$ A related study, by Dohmen et al. (2010), used a random sample of around 1,000 adults representative of the German population to show that higher cognitive ability is associated with lower risk aversion and less pronounced impatience. ${ }^{2}$ Finally. Booth, Cardona Sosa and Nolen (2011), in an experiment involving 231 college students in the UK, found a small statistically significant association between cognitive ability and the

\footnotetext{
${ }^{1}$ These authors collected three measures of cognitive skills: a nonverbal IQ test (Raven's matrices), a test of the ability to plan (the 'Hit 15' task), and a quantitative literacy (or numeracy) test. In their analysis they reported only the impact of IQ but they note that their results were robust to using the common factor obtained from a factor analysis of all three measures.

2 Dohmen et al. (2010) used two tests of cognitive ability that were similar to certain modules of the Wechsler Adult Intelligence Scale (WAIS). One was the symbol correspondence test, which asks subjects to match as many numbers and symbols as possible in 90 seconds according to a given correspondence. The other, the word fluency test, gives subjects a timed vocabulary test.
} 
probability of entering a real-stakes experimental lottery. Their measure of IQ was the twenty-minute version of the Raven's matrices.

The available literature on this topic is extremely small, so perhaps it is too early to conclude that the initial results represent 'stylised facts', especially as these 3 studies produce effects of very different magnitudes. However, in our present paper, our goal is not to replicate the above studies. Instead, it is to investigate if individual's risk preferences at age 20 are affected by an alternative measure of ability that is available through some surveys (rather than through tests administered by the research team). The ability measure that we utilise is the percentile ranking used for college entrance, measured at age 18 . We are also interested in explaining differences in risk preferences between young men and women, controlling for ability. To measure risk preferences we use information from a unique new birth cohort study. At wave 2 , conducted in 2008 , individuals were asked to selfassess their attitudes to risk. They were also asked to consider how they would invest lottery winnings. While the first question is relatively simple, the second is more complex since it involves a time dimension (the uncertain returns are not realised for two years) as well as a choice of six investment amounts. The relative simplicity of the risk attitudes questions and the complexity of the hypothetical lottery question mean that responses to the latter are more likely to be affected by issues of discounting, framing, broad bracketing and the like.

\section{The Data Source and Main Variables}

\subsection{The Data}

Our birth-cohort data - from the Youth in Focus Project (YIF) - are unique in providing detailed information about cognitive skills and family welfare histories, as well as individual and household attributes. The birth-cohort comprises young Australians who were aged 18 at the time of the first wave conducted in 2006. Measures of cognitive ability and demographic attributes were obtained from the first wave, while information about risk attitudes was obtained from the second wave carried out in 2008. Individuals were considered out-of-scope if institutionalized, unwell, overseas or in the armed forces. 
The YIF Project uses Australian administrative social security records to identify all young people born between October 1987 and March 1988 who appeared in the Centrelink administrative data between 1991 and July 2006 (Breunig et al., 2009; Cobb-Clark, Ryan and Sartbayeva, forthcoming). ${ }^{3}$ A comparison of the number of young adults in these administrative data with census data reveals that over 98 per cent of all young people born between October 1987 and March 1988 are represented in the administrative data (Breunig et al., 2009).

A stratified (on welfare history) random sample of young people was selected from the administrative data for interview by phone and through a self-completion questionnaire (SCQ). These data were then matched to the administrative social security data for the youth's family. ${ }^{4}$

\subsection{The Dependent Variables}

\section{Risk Attitudes}

The questions about risk attitudes were asked in the youth self-completion questionnaire in the second wave when individuals were aged 20. Each respondent was first asked: "How do you see yourself: Are you generally a person who is fully prepared to take risks or do you try to avoid taking risks?" Respondents were asked to rank themselves on an 11-point scale

\footnotetext{
${ }^{3}$ The Australian social security system is nearly universal for families with children. Some payments such as the Child Care Benefit have no income test at all, while others, such as the Family Tax Benefit, are denied only to families in the top quintile of the income distribution. At the other extreme are welfare payments targeted towards low-income parents (mainly single parents) or unemployed individuals, which are also subject to income, asset and/or activity tests. Young people are also in the administrative data if they receive benefits in their own right. However most are in the data because a family member (usually a parent) received a payment at some point between 1993 and 2005 which depended in part on his or her relationship to the youth. These social security records provide high-quality, fortnightly data on payment details for nearly the entire birth cohort.

${ }^{4}$ Following best practice (Groves et al., 2004), the survey team used approach letters, incentive payments, repeated call backs, and Computer Assisted Telephone Interviewing (CATI) to maximize response rates. While response rates differed somewhat across strata, these differences stemmed primarily from differences in contact rates rather than refusal rates (Breunig et al., 2009). Overall, 36.1 per cent of young people responded to the survey, 73.1 per cent of whom also completed the self-completion questionnaire. More than 96 per cent of youths consented to having these survey data linked to their administrative records.
} 
from 0 to 10 with 0 being labelled "avoid taking risks" and 10 as "fully prepared to take risks." ${ }^{5}$

The mean category for general risks is 5.6 and is significantly lower than the mean of just over 8.1 for financial risk. Clearly respondents are more willing to take financial risks than to take general risks, although the standard deviation of the financial risks variable is slightly larger. Inspection of Figures $1 a$ and $1 b$ (histograms for general risk and financial risk respectively) reveals that general risk is fairly normally distributed, while for financial risk the mass of the distribution is concentrated to the right, especially for women.

The Yif questionnaire also asked about attitudes to risk across a number of other domains, as we discuss in more detail towards the end of Section 4. These include attitudes to financial, driving, leisure, occupational, health, and 'faith in others' risks. ${ }^{6}$

Figure 1a: Histogram of Male and Female Attitudes to General Risk

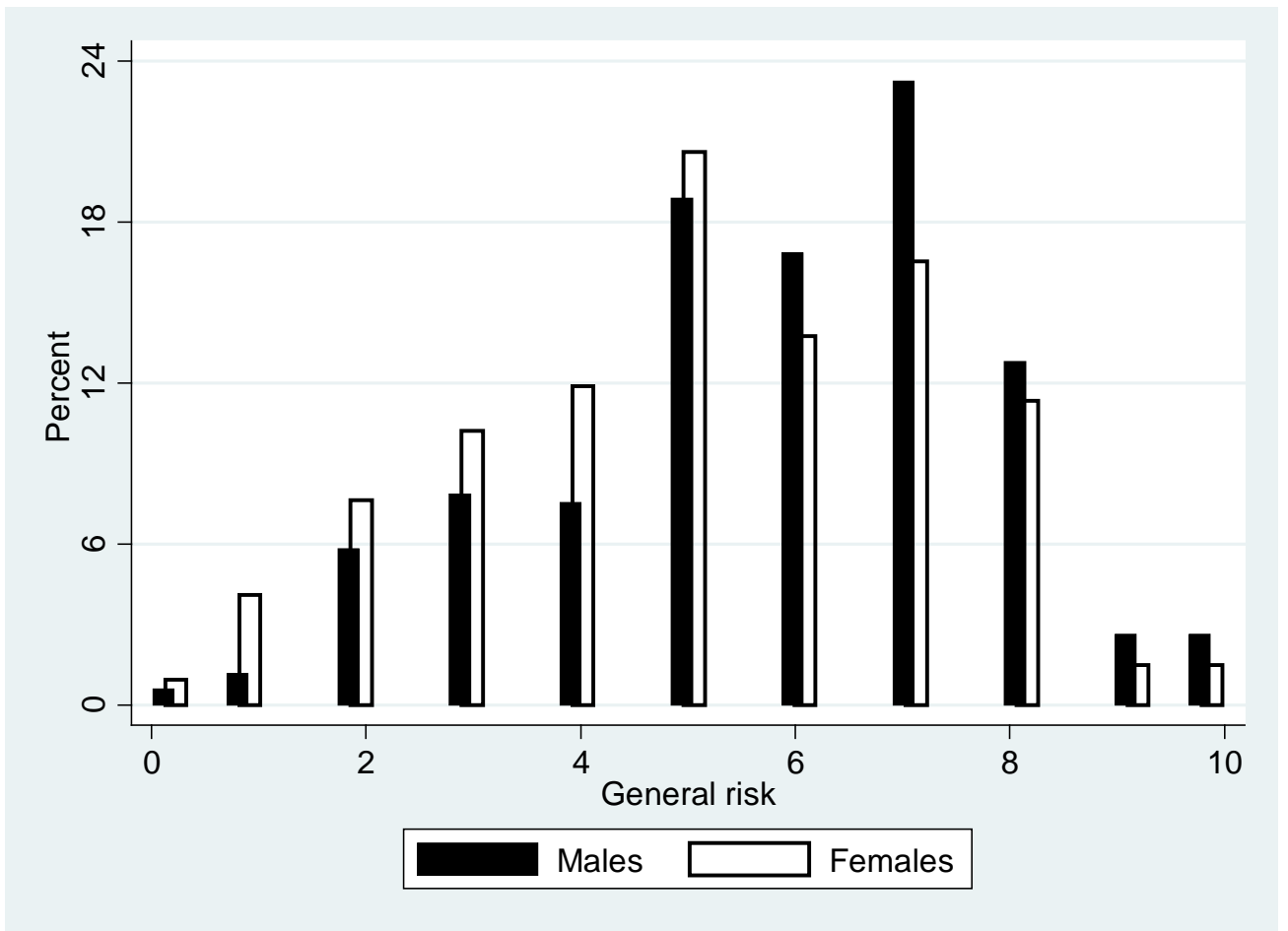

\footnotetext{
${ }^{5}$ A general risk question of this same form in the German Socio-Economic Panel Study (GSOEP) was experimentally validated by Dohmen et al (2006) and shown to be a reliable measure of an individual's actual propensity to take risks. Dohmen et al. (2006) used a pool of 450 subjects with characteristics comparable to the respondents of the GSOEP and conducted real-stakes lottery experiments. Participants in the experiment also answered the same general risk question from the SOEP questionnaire that is used in this paper. The responses turned out to be good predictors of actual risk taking behaviour in the paid experiment.

${ }^{6}$ The partial correlation coefficients between these risk domains range from 0.24 to 0.55 .
} 
Figure 1b: Histogram of Male and Female Attitudes to Financial Risk

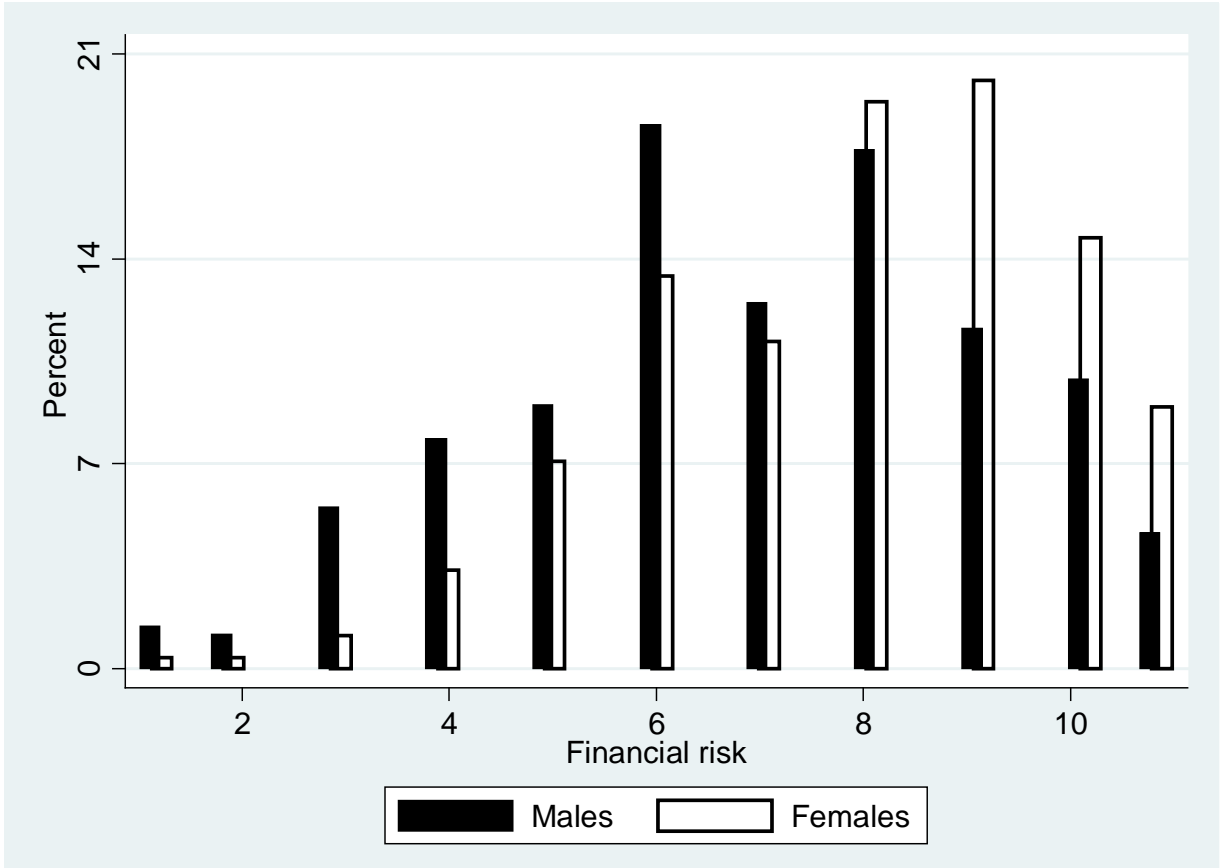

\section{Hypothetical Lottery Investment}

In the YIF questionnaire, respondents were next asked to consider the following hypothetical lottery: "Please consider what you would do in the following situation: Imagine that you had won 100,000 dollars in the lottery. Almost immediately after you collect the winnings, you receive the following financial offer from a reputable bank, the conditions of which are as follows: There is the chance to double the money within two years. It is equally possible that you could lose half the amount invested. You have the opportunity to invest the full amount, part of the amount, or reject the offer. What share of your lottery winnings would you be prepared to invest in this financially risky, yet lucrative investment? The subject then ticked a box indicating if $s /$ he would invest $A \$ 100,000, \$ 80,000, \$ 60,000$, $\$ 40,000, \$ 20,000$, or "Nothing, I would decline the offer." 7

We ordered categorically the responses to the hypothetical lottery question, such that a zero indicates that none of the $\$ 100,000$ is invested whereas a value of 5 indicates that all of the winnings are invested. The mean response is just under 1 (so the mean

\footnotetext{
${ }^{7}$ At the time of writing, A\$1was worth US\$0.96.
} 
amount invested is $\$ 20,000$ ) and the SD is just over 1 . Figures $1 \mathrm{c}$ shows the distribution of responses to the hypothetical lottery question. The mass of the distribution is concentrated on the left of the figure, which has relatively few high values, especially for women.

Figure 1c: Histogram of Male and Female Attitudes to Lottery Investment

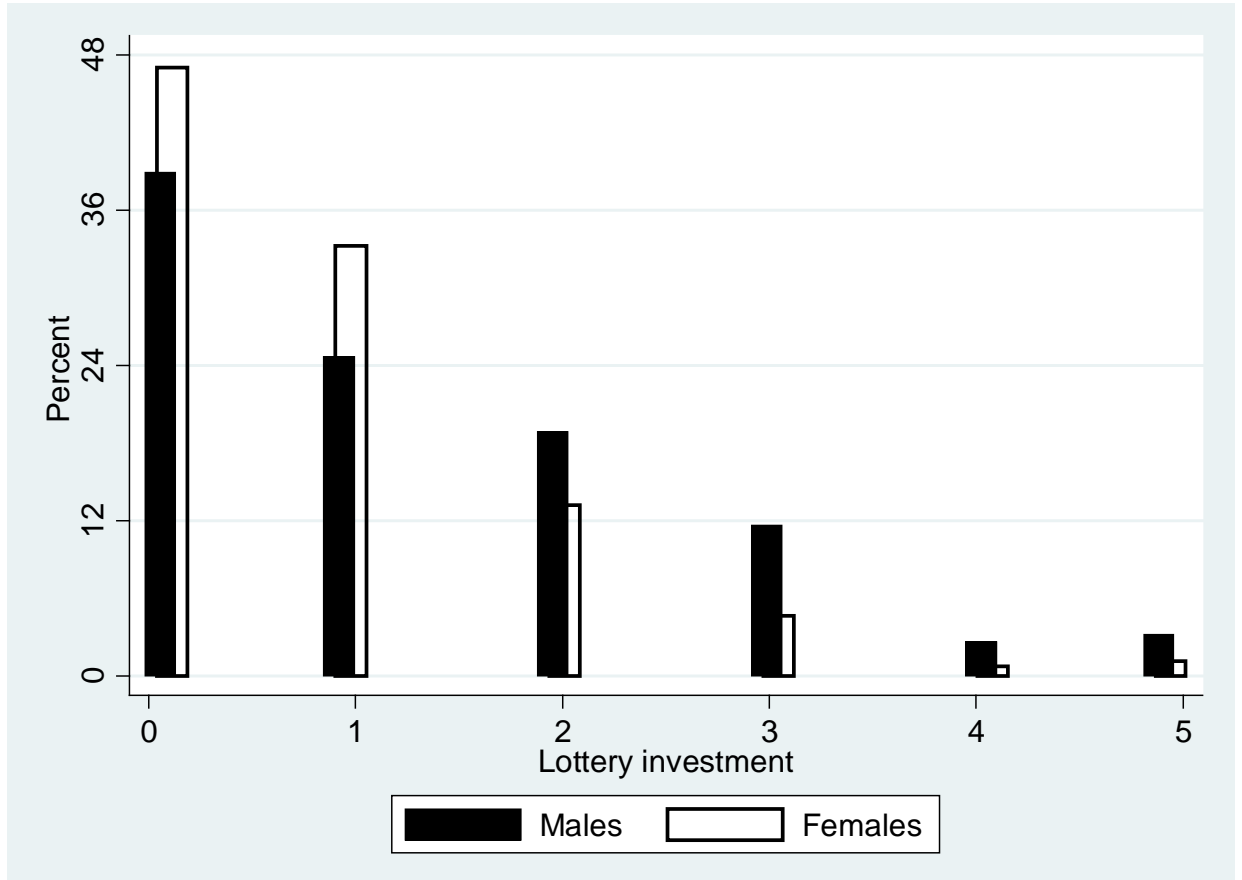

A priori we would expect different responses to the risk attitudes and the hypothetical lottery questions. The hypothetical lottery question is not as straightforward as the simple risk attitudes questions because it involves not only a time dimension (the outcome will not be realised until two years hence) and uncertain returns, but also a choice of investment amounts ${ }^{8}$. Moreover, the fact that it is more complex may raise narrow bracketing issues. $^{9}$

Risk aversion and impatience are conflated in responses to this question: patient individuals are more likely to be willing to wait for two years to receive returns than those who want their winnings now, ceteris paribus. If the returns were available immediately,

\footnotetext{
${ }^{8}$ See Andersen et al. (2008) for discussion of experiments designed to jointly elicit risk and time preferences.

${ }^{9}$ Rabin and Weizsacker (2009:1508) define narrow bracketing as where 'a decision maker who faces multiple decisions tends to choose an option... without full regard to the other decisions and circumstances that she faces'.
} 
then the expected value of the investment is clearly greater than the certainty-equivalent and any risk-neutral individual would invest everything in the lottery. Yet we shall see that individuals observed in the data do not do this, and this is likely to reflect their risk-aversion, their time preference, and whether they narrow or broad bracket the choices inherent in this question.

\subsection{Controls and sample selection issues}

We will be examining if risk preferences are correlated with cognitive ability and gender. While responses to cognitive ability ('score'), gender and other controls were collected at wave 1 , responses to the risk preferences variables were not collected until wave 2, as noted above. Therefore we wish to see if there are significant differences in the means of explanatory variables across waves 1 and 2 .

Before comparing the means across waves, we first define the variable we use to proxy cognitive skills. The variable 'score' is the percentile ranking for university entrance based on respondents' academic performance in grades 11 and 12 . This ranking is measured from 30.0 to $99.9 .^{10}$ Australian children begin school at age five, complete a further six years of primary school, and leave secondary school after finishing 12th grade. All students completing secondary school with minimum coursework requirements obtain a percentile ranking based on their academic performance in grades 11 and 12. In 2007, the share of women enrolled in university education in Australia was around $55 \%$ and gender parity had been achieved by 1987 (Booth and Kee, 2011). We might therefore expect a similar proportion would provide values for the variable 'score'. ${ }^{11}$ Indeed, in wave 1 , conducted in 2006 , the female percentage of the sample with usable responses including score is $57 \%$. Note however that in our sample the correlation between cognitive skills and female gender is very low, at 0.088 .

\footnotetext{
10 Australia comprises six states and two territories, and each calculates this ranking slightly differently. Rankings were therefore calibrated to an Australia-wide scale, ranging from 30 to 99.99. Unlike other states and territories, Queensland ranks students on a scale from 1 (highest) to 25 (lowest). Hence we use transformed scores for Queensland students, following Cardak and Ryan (2006), so that they are equivalent to those in other jurisdictions.

${ }^{11}$ Students wishing to go to university register their preferences (in rank order) for specific degree programs with a central administrative agency. University placement offers are made on the basis of students' entrance rankings (see Marks et al., 2001).
} 
Table 1: Comparing means across waves

\begin{tabular}{|c|c|c|c|c|}
\hline Variable & $\begin{array}{c}\begin{array}{c}\text { Wave } 1 \\
\text { usable } \\
\text { sample }\end{array} \\
{[1]} \\
\end{array}$ & $\begin{array}{c}\text { Subsample that } \\
\text { did not respond } \\
\text { to general risk } \\
\text { question } \\
\text { [2] }\end{array}$ & $\begin{array}{l}\text { Subsample that } \\
\text { responded to } \\
\text { general risk } \\
\text { question } \\
\text { [3] }\end{array}$ & Difference \\
\hline \multicolumn{5}{|l|}{ Dependent variables } \\
\hline General risk attitude & & & 5.59 & \\
\hline Financial risk attitude & & & 8.12 & \\
\hline Lottery investment & & & 0.98 & \\
\hline \multicolumn{5}{|l|}{ Individual attributes } \\
\hline Score & 71.77 & 68.06 & 74.74 & $-6.68 * * *$ \\
\hline Female & 0.57 & 0.53 & 0.61 & $-0.08 * * *$ \\
\hline Age & 18.66 & 18.66 & 18.66 & 0 \\
\hline Aboriginal & 0.02 & 0.02 & 0.01 & -0.01 \\
\hline \multicolumn{5}{|l|}{ Type of school } \\
\hline Government & 0.56 & 0.57 & 0.54 & 0.03 \\
\hline Catholic & 0.24 & 0.25 & 0.22 & 0.03 \\
\hline \multicolumn{5}{|l|}{$\begin{array}{l}\text { Parent's highest education } \\
\text { attained }\end{array}$} \\
\hline High school & 0.06 & 0.05 & 0.07 & -0.02 \\
\hline Certificate & 0.18 & 0.17 & 0.18 & -0.01 \\
\hline Diploma & 0.11 & 0.1 & 0.12 & -0.02 \\
\hline Bachelor & 0.16 & 0.14 & 0.17 & $-0.03 *$ \\
\hline Other & 0.03 & 0.03 & 0.03 & 0 \\
\hline Number of observations & 1586 & 704 & 882 & \\
\hline
\end{tabular}

Other demographic variables that we use as controls include whether or not the youth is Aboriginal, the youth's age, and the type of school he or she attended (nondenominational state school, Catholic school, or independent non-Catholic school). We also have information about the mother's highest educational qualifications. ${ }^{12}$ We have necessarily made a number of sample restrictions. Our estimating subsample comprises 882 Australian-born children-parent pairs present in both waves with valid information on all control variables (including parental responses to education). ${ }^{13}$ We drop all individuals not born in Australia. This was largely because we wished to ensure that our sample was

\footnotetext{
${ }^{12}$ A corresponding parent or guardian (in 96.5 per cent of cases the biological mother) was selected from the administrative data for a separate interview. The highest educational qualification of this individual is used in the regressions reported in some specifications in our paper.

${ }^{13}$ The full sample comprises 4079 cases, of whom 2684 were at school for the final exams and 1874 of whom provided valid information on the university entrance ranking (score). The restriction of obtaining valid information on risk attitudes in wave 2 left us with 1032 cases.
} 
Australian-educated, so that we could be more confident that the score variable would reflect cognitive skills (rather than cross-country differences in education systems).

The YiF dataset is rich in terms of data about income support, and in preliminary estimation we experimented with including these variables. In all cases the income support variables were statistically insignificant. Since their inclusion did not improve the explanatory power of our specifications but led to a considerable drop in the number of usable observations for our other variables of interest, we do not include these variables in the results reported in Section $3 .^{14}$

Table 1 presents, in columns [1] and [3], the means for the wave 1 sample (1586 cases) and wave 2 sample (882 cases) respectively. Column [2] displays the means for the subsample of wave 1 individuals who did not respond at wave 2 (704 cases). The final column gives the difference in means between the responding and non-responding subsamples. It shows that there are statistical differences for only three variables - score, female and having a parent with a university degree (though the last is significant only at the 10 confidence percent level).

Since our particular interest is in estimating the association between risk attitudes, and score and gender, we will therefore need to check if sample selection is a problem in our estimation by utilising appropriate sample selection models. To facilitate the interpretation of our results, we use standardized measures of the test scores in our econometric analysis. However, our results are robust if we instead use the nonstandardized measures (these estimates are available from the authors on request).

\footnotetext{
${ }^{14}$ The sample size dropped to 520 cases when we selected on cases with usable responses to welfare support in addition to usable responses to the other variables in which we are interested. In preliminary estimation using this subsample, we followed Cobb-Clark, Ryan and Sartbayeva (2009) in classifying young people into groups depending on the timing and intensity of the family's welfare receipt. Thus we included indicator variables for being on intensive welfare, moderate late welfare, and moderate early welfare, with the base being individuals in families with no history of welfare (and who appeared in the administrative data only through their family tax and child care benefit records). This categorization allowed us to control for the intensity and timing of family welfare receipt, which some argue is likely to affect risk preferences (see CobbClark et al, 2009, and references therein). Although is interesting that these variables were statistically insignificant, they are not the focus of our interest in the present paper.
} 


\subsubsection{Identification}

The YiF dataset contains a set of variables proxying respondents' 'sense of control'. ${ }^{15}$ According to the psychology literature (see for example Rotter, 1966), individuals are characterised by attitudes or beliefs about the relationship between their own behaviour and its consequences. Those individuals believing that their own efforts affect life's outcomes have what is described as an internal locus of control of 'self-efficacy', whereas those who believe that external factors such as 'luck' affect life's outcomes have an external locus of control (see Gatz and Karel, 1993). These variables in YiF have been used by Barón and Cobb-Clark (2010) to show that young people with a more 'internal locus of control' have a higher probability of finishing secondary school and, conditional on completion, meeting the requirements to obtain a university entrance rank. (Check correlation between Score and these variables.)

In our analysis we use these wave 1 'sense of control' variables as determinants of the probability of responding to the self-completion questionnaire (SCQ) in wave 2 . Our rationale for so doing is that individuals with a low 'sense of control' are likely to be less motivated to bother completing/returning the SCQ (since they think nothing they do will have any effect). We also include the predetermined variable taking the value one if the parent read to the child at night and zero otherwise. ${ }^{16}$ Pyschologists believe that such an

15 The questions designed to elicit individuals beliefs about control include the following, all of which are given on a four point scale ranging 1 (strongly disagree), 2 (Disagree), 3 (Agree), 4 (Strongly agree):

1. There is really no way I can solve some of the problems I have.

2. Sometimes I feel that I'm being pushed around in life.

3. I have little control over the things that happen to me.

4. I can do just about anything I set my mind to.

5. I often feel helpless in dealing with the problems of life.

6. What happens to me in the future mostly depends on me.

7. There is little I can do to change many of the most important things in my life.

The correlations between these questions and risk attitudes for those who responded the SCQ are very low, validating their use as exclusion restrictions: question 1- general risk: 0.0082; question 1- financial risk: 0.0023; question 1- lottery: 0.026; question 2- general risk: -0.0059; question 2- financial risk: -0.018 ; question 2- lottery: 0.0238; question 3- general risk: 0.0066; question 3- financial risk: 0.0075; question 3- lottery: 0.0072; question 4- general risk: -0.0011; question 4- financial risk: 0.0182; question 4- lottery: 0.006; question 5- general risk: -0.0172; question 5- financial risk: -0.0374; question 5- lottery: -0.0155; question 6- general risk: 0.0428; question 6- financial risk: 0.0265; question 6 - lottery: 0.0372; question 7 - general risk: -0.0119; question 7 - financial risk: -0.0021; question 7- lottery: 0.0141.

\footnotetext{
${ }^{16}$ When you were younger did your parents read to you at night? (1=Every night, 2=Often, 3=Sometimes,
} $4=$ Not very often, $5=$ Not at all). 
activity makes children feel more connected, and this might contribute to the probability an individual will return the SCQ.

\section{The Results}

We estimate ordered probit models of the determinants of general risk attitudes, of financial risk attitudes, and of the amount invested in the hypothetical risky financial investment. For each of these three risk outcomes, we estimated ordered probits with and without sample selection. These pairs of estimates are presented in Table 2 for each outcome. (The full set of estimates for the selection equations is presented in the online Appendix Table A.1, while the OLS estimates are presented in the online Appendix Table A.3.)

Excluded from the risk equations but included in the sample-selection equations are the variables measuring an individual's sense of control as well as the dummy variable indicating being read to at night as a child. None of these variables is correlated with risk attitudes but some of them are significantly correlated with the probability of responding to the wave 2 questionnaire. In all the selection equations, feeling helpless in dealing with the problems of life significantly decreases the probability of response and what happens to me in the future mostly depends on me significantly increases the probability. Also being read at night often or very often increases the probability of response significantly.

Notice from Table 2 that there is little difference in the magnitude of the estimated coefficients and the standard errors across the selection and non-selection ordered probit models. Moreover, observe that the estimated rho from the sample selection model indicating the degree of correlation between unobservables in the two equations - is not statistically significant. Hence the estimates in the first column in each pair of outcomes represent our preferred specification. 
Table 2. Risk Preferences: Ordered probit estimates with and without sample selection.

\section{General Risk \\ Financial Risk \\ Lottery Investment}

(from $0=$ "avoid taking risks" to $10=$ "fully prepared to take risks")

(from $0=$ "none of the $\$ 100,000$ is invested" to $5=$ "All of the winnings are invested")

\begin{tabular}{|c|c|c|c|c|c|c|}
\hline & & & & & \multicolumn{2}{|c|}{ are invested") } \\
\hline & $\begin{array}{c}\text { Ordered probit } \\
{[1]} \\
\end{array}$ & $\begin{array}{c}\text { Ordered probit } \\
\text { with selection } \\
{[2]} \\
\end{array}$ & $\begin{array}{c}\text { Ordered probit } \\
{[3]} \\
\end{array}$ & $\begin{array}{c}\text { Ordered probit } \\
\text { with selection } \\
{[4]}\end{array}$ & $\begin{array}{c}\text { Ordered probit } \\
{[5]}\end{array}$ & $\begin{array}{c}\text { Ordered probit } \\
\text { with selection } \\
{[6]}\end{array}$ \\
\hline Standardised score & $0.057(0.037)$ & $0.052(0.047)$ & $-0.016(0.037)$ & $-0.032(0.043)$ & $0.053(0.039)$ & $0.037(0.051)$ \\
\hline Female & $0.267 * * *(0.071)$ & $0.264 * * *(0.075)$ & $0.48 * * *(0.072)$ & $0.472 * * *(0.076)$ & $-0.376 * * *(0.077)$ & $-0.389 * * *(0.079)$ \\
\hline Age & $-0.042(0.19)$ & $-0.043(0.191)$ & $-0.119(0.19)$ & $-0.141(0.19)$ & $0.291(0.206)$ & $0.295(0.206)$ \\
\hline Aboriginal & $-0.429(0.297)$ & $-0.425(0.299)$ & $-0.266(0.299)$ & $-0.261(0.299)$ & $0.346(0.312)$ & $0.361(0.313)$ \\
\hline \multicolumn{7}{|l|}{ Type of school } \\
\hline Government & $0.131(0.087)$ & $0.133(0.088)$ & $0.184 * *(0.087)$ & $0.184 * *(0.087)$ & $-0.126(0.094)$ & $-0.124(0.096)$ \\
\hline Catholic & $0.073(0.102)$ & $0.077(0.106)$ & $0.095(0.103)$ & $0.102(0.105)$ & $-0.074(0.11)$ & $-0.07(0.114)$ \\
\hline \multicolumn{7}{|c|}{ Parent's highest education } \\
\hline High school & $0.136(0.138)$ & $0.129(0.143)$ & $0.214(0.139)$ & $0.199(0.142)$ & $-0.337 * *(0.152)$ & $-0.355^{* *}(0.156)$ \\
\hline Bachelor & 0.01 (0.099) & $0.007(0.101)$ & $0.241 * *(0.1)$ & $0.247 * *(0.101)$ & $-0.144(0.108)$ & $-0.16(0.109)$ \\
\hline Certificate & $0.102(0.096)$ & $0.099(0.097)$ & $0.079(0.096)$ & $0.073(0.097)$ & $-0.107(0.104)$ & $-0.108(0.104)$ \\
\hline Diploma & $0.101(0.112)$ & $0.098(0.114)$ & $0.081(0.112)$ & $0.072(0.114)$ & $-0.124(0.122)$ & $-0.135(0.123)$ \\
\hline Other & $0.196(0.218)$ & $0.194(0.218)$ & $0.413 *(0.221)$ & $0.409 *(0.221)$ & $-0.003(0.235)$ & $-0.006(0.235)$ \\
\hline Athro & - & $-0.036(0.236)$ & - & $-0.089(0.195)$ & - & $-0.135(0.266)$ \\
\hline Log-likelihood & -1847.293 & -2850.852 & -1848.825 & -2860.942 & -1166.09 & -2175.304 \\
\hline Pseudo R-squared & 0.0068 & - & 0.0155 & - & 0.0143 & - \\
\hline Observations & 882 & 1586 & 882 & 1586 & 882 & 1586 \\
\hline
\end{tabular}


Next, we consider each outcome in more detail, beginning with general risk attitudes. First consider the ordered probit estimates presented in column [1] of Table 2. Individuals with higher scores are more likely to be prepared to take general risks, although the impact is small and is not statistically significant. It is interesting that the girls are significantly more prepared to take risks than boys. None of the other controls is statistically significant. Indeed, the only significant variable is female. Next we turn to the ordered probit estimates of the willingness to take financial risks, displayed in columns [3] and [4] of Table 2. Cognitive skills have no statistically significant correlation with willingness to take financial risks. Again young women are more willing to take financial risks than young men, ceteris paribus. Individuals whose responding parent had a degree are more likely to take financial risks, as are those youths who attended state schools.

The YiF survey not only asked respondents about general risk attitudes but also about their risk attitudes in a number of specific domains. Elicited using the same 11-point scale, these questions covered: driving risk; financial risk; leisure risk; occupational risk; health risk; and faith in others risk. ${ }^{17}$ We present in the online Appendix Table A.2 a comparison of estimates for all risk categories. In summary, across all risk domains young women were significantly more likely than young men to report a greater willingness to take risks. The biggest effect, however, was found for financial risk. Notice also that there was no statistically significant correlation between score and willingness to take any form of risk.

Columns [5] and [6] of Table 2 report ordered probit estimates of the willingness to invest a proportion of the hypothetical lottery winnings in a risky financial investment. ${ }^{18}$ Cognitive ability, as proxied by score, has an economically and statistically insignificant impact on the amounts placed in the risky financial investment.

Being female is again statistically significant but notice that the sign is now negative: young women are less willing to use their lottery winnings to make the risky financial

\footnotetext{
17 The partial correlation coefficients between these risk domains are: general-driving: 0.2914; generalfinancial: 0.3854; general-leisure: 0.5488; general-occupational: 0.4480; general-health: 0.3581; general-faith in others: 0.3618; driving-financial: 0.4005; driving-leisure: 0.3065; driving-occupational: 0.3882; drivinghealth: 0.4823; driving-faith in others: 0.2424; financial-leisure: 0.3882; financial-occupational: 0.3847 ; financial-health: 0.3853; financial-faith in others: 0.2926; leisure-occupational: 0.4506; leisure-health: 0.2857; leisure-faith in others: 0.3145 ; occupational-health: 0.4170 ; occupational-faith in others: 0.3274 ; and healthfaith in others: 0.3631

${ }^{18}$ See Donkers, Bas, Bertrand Melenberg and Arthur Van Soest (2001) for a classic paper estimating risk attitudes from a lottery.
} 
investment than young men. The other demographic variables have no effect, with the exception of parental highest educational level being high school, which is negatively correlated.

We also estimated models dropping all controls except for the female gender dummy. Our estimates from this exercise are very similar to those reported in Table 2. The estimated coefficient to gender in the general risk model becomes slightly larger, at 0.283 for the non-selection model and 0.272 for the selection model. This compares with the gender coefficients of 0.267 and 0.264 in Table 2 reporting the general risk estimates with all the controls. Analogously, for the financial risk models, we find that the estimated coefficient for female gender when it is the only control is 0.47 in the non-selection model and 0.454 in the selection model. This compares with the gender coefficients of 0.48 and 0.472 in the middle pair of columns in Table 2, which report the financial risk estimates with all controls. Finally, for the lottery investment model, we find that the estimated coefficient for female gender when it is the only control is -0.358 in the non-selection model and -0.352 in the selection model. This compares with the gender coefficients of -0.376 and -0.389 in the last two columns of Table 2 reporting the lottery investment estimates with all controls.

As noted earlier, we expected different responses to the risk attitudes and the hypothetical lottery questions. This was for several reasons. First, the simplicity of the risk attitudes questions and the complexity of the hypothetical lottery question mean that responses to the latter are more likely to be affected by issues of framing, broad bracketing and the like. Second, risk aversion and impatience are conflated in responses to the hypothetical lottery question: patient individuals will be more willing to wait for two years to receive returns than those who want their winnings now. If the returns were available immediately, then the expected value of the investment is clearly greater than the certainty-equivalent and any risk-neutral individual would invest everything in the lottery.Yet we see that young women observed in the data are less likely than young men to do this, in spite of the fact that they were more likely than young men to be willing to take general and financial risks (a finding that is robust across all the risk domains - see the online Appendix Table A.2). This difference between the impact of gender on risk attitudes and the hypothetical lottery investment suggests that impatience and framing affects young women and men differently. 
Though much has been written on time preferences, the only study we could find that directly estimated gender differences in time preferences was that of Dohmen et al. (2010). ${ }^{19}$ Their measure of impatience was significantly increasing in female gender (this corresponds to greater impatience for women than for men) and the estimated coefficient was large. This finding is consistent with our results. While women in our sample report themselves as being more willing than men to take financial risks, this does not translate into a willingness to invest more in our lottery, the returns from which would not be received until two years down the track.

An interesting aspect of our results is that - for the risk attitudes questions - we find a gender effect of a different sign to that found in some of the literature. As summarized in Eckel and Grossman (2008), the majority (but not all) of experimental studies have found that women are more risk averse than men. However there is considerable heterogeneity across the literature in estimates of the association between gender and risk attitudes, as a reading of both Eckel and Grossman (2008) and Schubert et al. (1999) makes clear. Such heterogeneity could arise from different datasets, time periods, or cultural factors. In this context, our results should be regarded as summarising risk attitudes of the birth-cohort of young Australians aged 18 at the time of the first wave conducted in 2006, and who completed secondary school with minimum coursework requirements. While this birthcohort may not be typical of the population at large, it nonetheless provides an interesting perspective of youth attitudes to risk.

Eckel and Grossman (2008) also note that 'both field and lab studies typically fail to control for knowledge, wealth, marital status and other demographic factors that might bias male/female differences in risky choices.' These are the sorts of attributes that we have been able to control for in our analysis using the YIF dataset. However, our estimates of the gender effect when no controls are included are remarkably similar to the estimated gender effect with controls. This similarity in models with and without controls does not lend support to the notion that omitted variables might be biasing the estimated results.

\footnotetext{
19 The dependent variable in Dohmen et al. (2010) was the switching row in an intertemporal choice experiment. Subjects were presented with a choice table of 20 rows and asked to make a choice in each row. The decision experiment was always between 100 euros "today" and a larger amount that would be received 12 months in the future. Moving down the table, the early payment was always 100 euros but the size of the delayed payment increased in each subsequent row.
} 
Finally, in order to provide an easy interpretation of the magnitude of the estimated coefficients, we also estimated all the non-selection specifications in Table 2 by ordinary least squares (OLS). The ordered probit and OLS results are compared in the online Appendix Table A.3. There it can be seen that, using OLS estimation, women report themselves half a category higher than men for willingness to take general risks, and just over one category higher than men for willingness to take financial risks. For the lottery investment, the OLS estimates show that women invest less than comparable men by around $A \$ 3,800$. Moreover, youths whose responding parent had a high school education invested about $\$ 3,550$ less than the base of a lower education level.

\section{Robustness}

The inclusion of score in the analysis reported above reduced our estimating sample from 1152 cases with usable responses for risk and other controls to 882 cases. As a check on the robustness of the estimated coefficients to female gender presented in Table 2, we next report the results when we drop score from the analysis and re-estimate on the sample of 1152 cases and include only female gender as a control. Our results are given in Table 3.

Table 3: Ordered Probit Estimates, full sample with usable risk responses

\begin{tabular}{|c|c|c|c|}
\hline Dependent variable & \multicolumn{2}{|c|}{$\begin{array}{l}\text { (from } 0=\text { "avoid taking risks" to } \\
10=" \text { fully prepared to take risks") }\end{array}$} & $\begin{array}{c}{[3]} \\
\text { Lottery } \\
\text { (from } 0=" \text { none of } \\
\text { the } \$ 100,000 \text { is } \\
\text { invested" to } \\
5=\text { "All of the } \\
\text { winnings are } \\
\text { invested") }\end{array}$ \\
\hline Female & $0.187 * * *(0.061)$ & $0.414 * * *(0.1)$ & $-0.342 * * *(0.066)$ \\
\hline Log-likelihood & -2431.851 & -2457.864 & -1522.414 \\
\hline Pseudo R-squared & 0.0019 & 0.009 & 0.0086 \\
\hline Observations & 1152 & 1152 & 1152 \\
\hline
\end{tabular}

Notes: Standard errors in parenthesis; *,** and $* * *$ denote $10 \%, 5 \%$ and $1 \%$ levels of significance respectively. 
Notice from Column [1] that, in this larger sample including cases with missing score, women remain significantly more likely than men to report willingness to take general risks. However the magnitude of this coefficient is around two-thirds of its original size. From the second column, we see that women are as likely in this sample to take financial risks as in the slightly smaller sample represented in Table 2 . Finally, note from the third column that women remain less likely to invest lottery winnings. Thus our gender findings are robust across the subsamples. ${ }^{20}$

\section{Conclusion}

In this paper we utilised data from a unique new birth-cohort study, the Youth in Focus Project (YIF), to see how the risk preferences of young people are affected by cognitive skills and gender. Our measure of cognitive skills was the percentile ranking used for Australiawide university entrance at age 18 . We found that cognitive ability has no effect on risk preferences measured at age 20. This is in contrast to the three experimental studies investigating this issue using IQ measures to proxy cognitive skills.

However we found that gender has a statistically significant effect on young people's risk preferences. While young women are significantly more likely than young men to assess themselves as being prepared to take risks across all domains, women choose to invest significantly less when they are confronted with a clearly specified investment decision based on hypothetical lottery winnings.

Risk aversion and impatience are conflated in responses to the hypothetical lottery question: patient individuals will be more willing to wait for two years to receive returns than those who want their winnings now. If the returns were available immediately, then the expected value of the investment is clearly greater than the certainty-equivalent and any risk-neutral individual would invest everything in the lottery. Yet we see that young women observed in our birth-cohort data are less likely than young men to do this, in spite of the fact that they were more likely than young men to assess themselves as willing to

\footnotetext{
${ }^{20}$ A referee suggested that a potential issue with the subjective measure of risk aversion is differential reporting behavior of men and women, since the response scale is also subjective. The average woman may denote the same behavior as much more risk taking than the average man, and this difference in response scales might dominate the difference in actual behavior (see for example, King et al., (2004). We are unable to address that issue here, but future survey designers should bear this in mind.
} 
take risks across all the risk domains. This difference between the impact of gender on risk attitudes and the hypothetical lottery investment suggests that impatience and framing affects young women and men differently. Dohmen et al. (2010) found that their experimental measure of impatience is increasing in female gender, which corresponds to greater impatience for women than for men. This finding is consistent with our results. Although young women in our birth-cohort sample report themselves as being more willing than men to take financial risks, this does not translate into a willingness to invest more in a hypothetical lottery whose returns would not be received until two years down the track. 


\section{References}

Andersen, S., Harrison, G. W., Lau, M. I. and Rutström, E. E. (2008). 'Eliciting Risk and Time Preferences.' Econometrica, 76: 583-618.

Barón, J.D. and D. Cobb-Clark (2010). ‘Are Young People’s Educational Outcomes Linked to their Sense of Control?' IZA DP No. 4907

Booth, A.L., L. Cardona SosaP. Nolen. (2011). 'Gender Differences in Risk Aversion: Do Single-Sex Environments Affect their Development? ' London: CEPR Discussion Paper 8690.

Booth, A.L. and Kee (2011). 'A Long-Run View Of The University Gender Gap In Australia'. Australian Economic History Review, Vol. 51, No. 3 November 2011.

Breunig, R., D. Cobb-Clark, T. Gorgens, and A. Sartbayeva (2009, September). 'User's guide to the Youth in Focus Project, version 2.0.' Youth in Focus Project Discussion Paper Series No. 1. The Australian National University, Research School of Social Sciences (Economics Program), Canberra, Australia.

Burks S.V., J.P. Carpenter, L. Goette and A. Rustichini (2009). 'Cognitive skills affect economic preferences, strategic behavior, and job attachment.' Proceedings of the National Academy of Sciences of the USA. 106 (19): 7745-7750.

Cardak, B. A. and C. Ryan (2006, June). Why are high ability individuals from poor backgrounds under-represented at university? Discussion Paper No. A06.04, La Trobe University, Melbourne, Australia.

Cobb-Clark, D., C.Ryan and A. Sartbayeva (2009). 'Taking Chances: The Effect of Growing Up on Welfare on the Risky Behavior of Young People.' IZA DP No. 4095. Forthcoming Scandinavian Journal of Economics.

Dohmen, T. J., A. Falk, D. Huffman, J. Schupp, U. Sunder and G. G. Wagner (2006). 'Individual Risk Attitudes: New Evidence from a Large, Representative, Experimentally-Validated Survey' (February). CEPR Discussion Paper No. 5517. Forthcoming Journal of the European Economic Association.

Dohmen TJ, A. Falk, D. Huffman and U. Sunde (2010). 'Are Risk Aversion and Impatience Related to Cognitive Ability?' American Economic Review, 2010, 100 (3), 1238-1260.

Donkers, B., B. Melenberg and A. Van Soest (2001). 'Estimating risk attitudes using lotteries: A large sample approach'. Journal of Risk and Uncertainty, 22(2), 165-195.

Eckel, C., and P. Grossman (2008). Men, Women and Risk Aversion: Experimental Evidence. Chapter 114, pp 1078-1086, in Handbook of Experimental Economics Results, (eds) 
Charles R. Plott, Vernon L. Smith. Elsevier Science B.V./North-Holland, Amsterdam, The Netherlands.

Gatz, M. and M.J. Karel (1993). 'Individual change in perceived control over 20 years. International Journal of Behavioral Development 16 (2), 305\{322.

Holt, C.A. and S.K. Laury (2002). Risk Aversion and Incentive Effects. The American Economic Review Vol. 92, No. 5 (Dec., 2002), pp. 1644-1655.

King, G, Murray, CJL, Salomon, JA and Tandon, A. 2004. 'Enhancing the Validity and CrossCultural Comparability of Measurement in Survey Research,'American Political Science Review, 98(1), pp. 191-207.Marks, G. N., J. McMillan, and K. Hillman (2001). Tertiary entrance performance: the role of student background and school factors. Research Report 22, Australian Council for Educational Research, Longitudinal Surveys of Australian Youth, Melbourne, Australia.

Rabin, M. and G. Weizsäcker (2009). Narrow Bracketing and Dominated Choices. The American Economic Review, Volume 99, Number 4, September , pp. 1508-1543(36)

Read, D., G. Loewenstein and M. Rabin (1999). 'Choice Bracketing'. Journal of Risk and Uncertainty, Volume 19, Numbers 1-3, 171-197.

Rotter, J. (1966). Generalized expectancies of internal versus external control of reinforcements. Psychological Monographs, 80.

Schubert, R., M. Brown, M. Gysler and H.W. Brachinger (1999). 'Financial Decision-Making: Are Women Really More Risk-Averse?' American Economic Review, 89(2),. 381-385, May.

Tversky, A. and D. Kahneman (1981). 'The framing of decisions and the psychology of choice'. Science, Vol 211, Issue 4481, 453-458.

Tversky, A. and D. Kahneman (1986). 'Rational Choice and the Framing of Decisions'. The Journal of Business, Vol. 59, No. 4, Part 2: The Behavioral Foundations of Economic Theory. (Oct.), pp. S251-S278. 
Table A1. Risk Preferences: Ordered probit estimates with and without sample selection.

\section{General Risk \\ Financial Risk \\ Lottery Investment}

(from $0=$ "avoid taking risks" to $10=$ "fully prepared to take risks")

(from $0=$ "none of the $\$ 100,000$ is invested" to $5=$ "All of the winnings are invested")

\begin{tabular}{|c|c|c|c|c|c|c|}
\hline & \multirow[b]{2}{*}{$\begin{array}{c}\text { Ordered probit } \\
{[1]}\end{array}$} & \multirow[b]{2}{*}{$\begin{array}{c}\text { Ordered probit } \\
\text { with selection } \\
{[2]}\end{array}$} & \multirow[b]{2}{*}{$\begin{array}{c}\text { Ordered probit } \\
\text { [3] }\end{array}$} & \multirow[b]{2}{*}{$\begin{array}{c}\text { Ordered probit } \\
\text { with selection } \\
{[4]}\end{array}$} & \\
\hline & & & & & $\begin{array}{l}\text { Ordered probit } \\
\text { [5] }\end{array}$ & $\begin{array}{c}\text { Ordered probit } \\
\text { with selection } \\
{[6]}\end{array}$ \\
\hline Standardised score & $0.057(0.037)$ & $0.052(0.047)$ & $-0.016(0.037)$ & $-0.032(0.043)$ & $0.053(0.039)$ & $0.037(0.051)$ \\
\hline Female & $0.267^{* * *}(0.071)$ & $0.264^{* * *}(0.075)$ & $0.48^{* * *}(0.072)$ & $0.472^{* * *}(0.076)$ & $-0.376 * * *(0.077)$ & $-0.389 * * *(0.079)$ \\
\hline Age & $-0.042(0.19)$ & $-0.043(0.191)$ & $-0.119(0.19)$ & $-0.141(0.19)$ & $0.291(0.206)$ & $0.295(0.206)$ \\
\hline Aboriginal & $-0.429(0.297)$ & $-0.425(0.299)$ & $-0.266(0.299)$ & $-0.261(0.299)$ & $0.346(0.312)$ & $0.361(0.313)$ \\
\hline \multicolumn{7}{|l|}{ Type of school } \\
\hline Government & $0.131(0.087)$ & $0.133(0.088)$ & $0.184 * *(0.087)$ & $0.184 * *(0.087)$ & $-0.126(0.094)$ & $-0.124(0.096)$ \\
\hline Catholic & $0.073(0.102)$ & $0.077(0.106)$ & $0.095(0.103)$ & $0.102(0.105)$ & $-0.074(0.11)$ & $-0.07(0.114)$ \\
\hline \multicolumn{7}{|c|}{ Parent's highest education } \\
\hline High school & $0.136(0.138)$ & $0.129(0.143)$ & $0.214(0.139)$ & $0.199(0.142)$ & $-0.337 * *(0.152)$ & $-0.355^{* *}(0.156)$ \\
\hline Bachelor & $0.01(0.099)$ & $0.007(0.101)$ & $0.241 * *(0.1)$ & $0.247^{* *}(0.101)$ & $-0.144(0.108)$ & $-0.16(0.109)$ \\
\hline Certificate & $0.102(0.096)$ & $0.099(0.097)$ & $0.079(0.096)$ & $0.073(0.097)$ & $-0.107(0.104)$ & $-0.108(0.104)$ \\
\hline Diploma & $0.101(0.112)$ & $0.098(0.114)$ & $0.081(0.112)$ & $0.072(0.114)$ & $-0.124(0.122)$ & $-0.135(0.123)$ \\
\hline Other & $0.196(0.218)$ & $0.194(0.218)$ & $0.413 *(0.221)$ & $0.409 *(0.221)$ & $-0.003(0.235)$ & $-0.006(0.235)$ \\
\hline \multicolumn{7}{|l|}{ Selection model } \\
\hline \multicolumn{7}{|c|}{ There is really no way I can solve some of the problems I have (Base: Strongly disagree) } \\
\hline Disagree & & $-0.027(0.097)$ & & $-0.029(0.098)$ & & $-0.01(0.098)$ \\
\hline Agree & & $0.052(0.132)$ & & $0.052(0.132)$ & & $0.061(0.131)$ \\
\hline
\end{tabular}


Sometimes I feel that I'm being pushed around in life (Base: Strongly disagree)

Disagree $0.01(0.114)$ $0.006(0.127)$

$0.012(0.114)$

$0.017(0.114)$

Agree

$-0.174(0.266)$

$0.019(0.127)$

$0.04(0.131)$

Strongly agree

$-0.193(0.265)$

I have little control over the things that happen to me (Base: Strongly disagree)

Disagree

$0.065(0.097)$

$0.058(0.097)$

$0.053(0.097)$

Agree

$0.087(0.151)$

$0.064(0.15)$

Strongly agree

$0.178(0.358)$

$0.147(0.357)$

$0.195(0.362)$

I can do just about anything I set my mind to (Base: Strongly disagree)

Disagree

Agree

$0.5(0.322)$

$0.531 *(0.322)$

$0.451(0.292)$

$0.475(0.333)$

Strongly agree

0.384

$0.403(0.288)$

$0.391(0.3)$

$0.346(0.296)$

I often feel helpless in dealing with the problems of life (Base: Strongly disagree)

Disagree

$-0.127(0.113)$

$-0.129(0.113)$

$-0.204(0.139)$

$-0.131(0.113)$

$-0.2(0.142)$

$-0.077(0.234)$

$0.213(0.139)$

ongree

$-0.138(0.233)$

$-0.084(0.232)$

What happens to me in the future mostly depends on me (Base: Strongly disagree)

\begin{tabular}{llll} 
Disagree & $0.682^{* *}(0.34)$ & $0.657^{*}(0.338)$ & $0.664^{* *}(0.338)$ \\
Agree & $0.608^{* *}(0.291)$ & $0.592^{* *}(0.289)$ & $0.618^{* *}(0.292)$ \\
Strongly agree & $0.719^{* *}(0.29)$ & $0.689^{* *}(0.289)$ & $0.725^{* *}(0.392)$ \\
\hline
\end{tabular}

There is little I can do to change many of the most important things in my life (Base: Strongly disagree)

Agree $0.056(0.145)$

$0.056(0.145)$

$-0.073(0.092)$

$-0.07(0.092)$

$0.046(0.144)$

$0.057(0.145)$

Strongly agree

$0.362(0.346)$

When you were younger did your parents read to you at night? (Base: Every night)

Often

$-0.3 * * *(0.107)$

$-0.287^{* * *}(0.104)$

$-0.287^{* * *}(0.104)$

Sometimes

$-0.342 * * *(0.113)$

$-0.345 * * *(0.112)$

$-0.34 * * *(0.113)$ 


\begin{tabular}{|c|c|c|c|c|c|c|}
\hline Not very often & & $-0.126(0.138)$ & & $-0.122(0.138)$ & & $-0.12(0.138)$ \\
\hline Not at all & & $-0.253(0.174)$ & & $-0.256(0.173)$ & & $-0.241(0.177)$ \\
\hline Standardised score & & $0.196 * * *(0.035)$ & & $0.19 * * *(0.035)$ & & $0.189 * * *(0.035)$ \\
\hline Female & & $0.153 * *(0.069)$ & & $0.158 * *(0.069)$ & & $0.161^{* *}(0.069)$ \\
\hline Age & & $0.154(0.184)$ & & $0.108(0.184)$ & & $0.106(0.184)$ \\
\hline Aboriginal & & $-0.071(0.258)$ & & $-0.079(0.258)$ & & $-0.081(0.258)$ \\
\hline \multicolumn{7}{|l|}{ Type of school } \\
\hline Government & & $-0.136(0.087)$ & & $-0.138(0.087)$ & & $-0.151 *(0.088)$ \\
\hline Catholic & & $-0.23 * *(0.1)$ & & $-0.229 * *(0.1)$ & & $-0.244 * *(0.101)$ \\
\hline \multicolumn{7}{|c|}{ Parent's highest education } \\
\hline High school & & $0.175(0.143)$ & & $0.17(0.143)$ & & $0.171^{* *}(0.142)$ \\
\hline Bachelor & & $0.055(0.099)$ & & $0.07(0.099)$ & & $0.071(0.099)$ \\
\hline Certificate & & $0.097(0.092)$ & & $0.092(0.092)$ & & $0.102(0.092)$ \\
\hline Diploma & & $0.145(0.111)$ & & $0.139(0.111)$ & & $0.139(0.111)$ \\
\hline Other & & $-0.053(0.209)$ & & $-0.064(0.209)$ & & $-0.06(0.209)$ \\
\hline Constant & & $-3.481(3.434)$ & & $-2.634(3.435)$ & & $-2.581(3.441)$ \\
\hline Athro & - & $-0.036(0.236)$ & - & $-0.089(0.195)$ & - & $-0.135(0.266)$ \\
\hline Log-likelihood & -1847.293 & -2850.852 & -1848.825 & -2860.942 & -1166.09 & -2175.304 \\
\hline Pseudo R-squared & 0.0068 & - & 0.0155 & - & 0.0143 & - \\
\hline Observations & 882 & 1586 & 882 & 1586 & 882 & 1586 \\
\hline
\end{tabular}

Notes: Standard errors in parenthesis. Asterisks denote levels of significance of a mean comparison t-test: *10 per cent, **5 per cent, ***1 per cent. According to the definition of 'athro', if 'rho' (correlation between error terms of the two regressions) is close to zero, so is 'athrho' and there's no evidence of sample selection. 
Table A2. Risk Preferences: Ordered probit estimates. Estimates without sample selection.

\begin{tabular}{|c|c|c|c|c|c|c|c|c|}
\hline & \multicolumn{7}{|c|}{ (from $0="$ avoid taking risks" to $10="$ fully prepared to take risks") } & $\begin{array}{c}\text { Lottery } \\
\text { investment } \\
\text { (from } 0=\text { "none } \\
\text { of the } \\
\$ 100,000 \text { is } \\
\text { invested" to } \\
5=" \text { All of the } \\
\text { winnings are } \\
\text { invested") }\end{array}$ \\
\hline $\begin{array}{l}\text { Standardised } \\
\text { score }\end{array}$ & $-0.016(0.037)$ & $0.057(0.037)$ & $0.029(0.037)$ & $0.003(0.037)$ & $-0.051(0.037)$ & $0.008(0.037)$ & $-0.001(0.037)$ & $0.053(0.039)$ \\
\hline Female & $\begin{array}{l}0.48 * * * \\
(0.072)\end{array}$ & $\begin{array}{c}0.267 * * * \\
(0.071)\end{array}$ & $\begin{array}{c}0.406 * * * \\
(0.072)\end{array}$ & $\begin{array}{c}0.452 * * * \\
(0.072)\end{array}$ & $\begin{array}{c}0.183^{* *} \\
(0.071)\end{array}$ & $\begin{array}{c}0.308^{* * *} \\
(0.071)\end{array}$ & $0.16 * *(0.071)$ & $\begin{array}{c}-0.376 * * * \\
(0.077)\end{array}$ \\
\hline Age & $-0.119(0.19)$ & $-0.042(0.19)$ & $\begin{array}{c}-0.304 \\
(0.193) \\
\end{array}$ & $0.049(0.19)$ & $-0.075(0.19)$ & $0.136(0.191)$ & $-0.059(0.189)$ & $0.291(0.206)$ \\
\hline Aboriginal & $-0.266(0.299)$ & $\begin{array}{c}-0.429 \\
(0.297)\end{array}$ & $0.102(0.306)$ & $-0.013(0.297)$ & $-0.129(0.3)$ & $0.177(0.3)$ & $0.339(0.3)$ & $0.346(0.312)$ \\
\hline $\begin{array}{l}\text { Type of school } \\
\text { Government }\end{array}$ & $\begin{array}{c}0.184 * * \\
(0.087)\end{array}$ & $0.131(0.087)$ & $0.084(0.088)$ & $0.079(0.086)$ & $-0.059(0.087)$ & $0.017(0.087)$ & $0.025(0.086)$ & $-0.126(0.094)$ \\
\hline Catholic & $0.095(0.103)$ & $0.073(0.102)$ & $\begin{array}{l}-0.073 \\
(0.103) \\
\end{array}$ & $-0.008(0.102)$ & $-0.16(0.102)$ & $-0.05(0.103)$ & $-0.073(0.102)$ & $-0.074(0.11)$ \\
\hline \multicolumn{9}{|c|}{ Parent's highest education } \\
\hline High school & $0.214(0.139)$ & $0.136(0.138)$ & $0.161(0.14)$ & $-0.034(0.138)$ & $0.096(0.138)$ & $0.139(0.139)$ & $-0.219(0.138)$ & $\begin{array}{c}-0.337^{* *} \\
(0.152)\end{array}$ \\
\hline Bachelor & $0.241 * *(0.1)$ & $0.01(0.099)$ & $0.13(0.101)$ & $-0.031(0.099)$ & 0.024 (0.099) & $0.073(0.1)$ & $-0.048(0.099)$ & $-0.144(0.108)$ \\
\hline Certificate & $0.079(0.096)$ & $0.102(0.096)$ & $0.032(0.097)$ & $-0.039(0.096)$ & $0.13(0.096)$ & $0.078(0.097)$ & $-0.137(0.096)$ & $-0.107(0.104)$ \\
\hline Diploma & $0.081(0.112)$ & $0.101(0.112)$ & $\begin{array}{l}-0.163 \\
(0.113)\end{array}$ & $-0.046(0.112)$ & $-0.118(0.112)$ & $\begin{array}{l}-0.149 \\
(0.113)\end{array}$ & $-0.019(0.112)$ & $-0.124(0.122)$ \\
\hline Other & $0.413 *(0.221)$ & $0.196(0.218)$ & $0.224(0.221)$ & $0.305(0.217)$ & $0.236(0.217)$ & $0.196(0.218)$ & $0.22(0.217)$ & $-0.003(0.235)$ \\
\hline Log-likelihood & -1848.825 & -1847.293 & -1836.429 & -1949.949 & -1983.111 & -1935.686 & -2028.286 & -1166.09 \\
\hline
\end{tabular}




\begin{tabular}{|c|c|c|c|c|c|c|c|c|}
\hline $\begin{array}{l}\text { Pseudo R- } \\
\text { squared }\end{array}$ & 0.0155 & 0.0068 & 0.0124 & 0.0119 & 0.004 & 0.0066 & 0.0035 & 0.0143 \\
\hline Observations & 882 & 882 & 882 & 882 & 882 & 882 & 882 & 882 \\
\hline
\end{tabular}

Notes: Standard errors in parenthesis. Asterisks denote levels of significance of a mean comparison $t$-test: ${ }^{*} 10$ per cent, ${ }^{* *} 5$ per cent, ${ }^{* * *} 1$ per cent. 
Table A3. Risk Preferences: Ordered probit and OLS estimates.

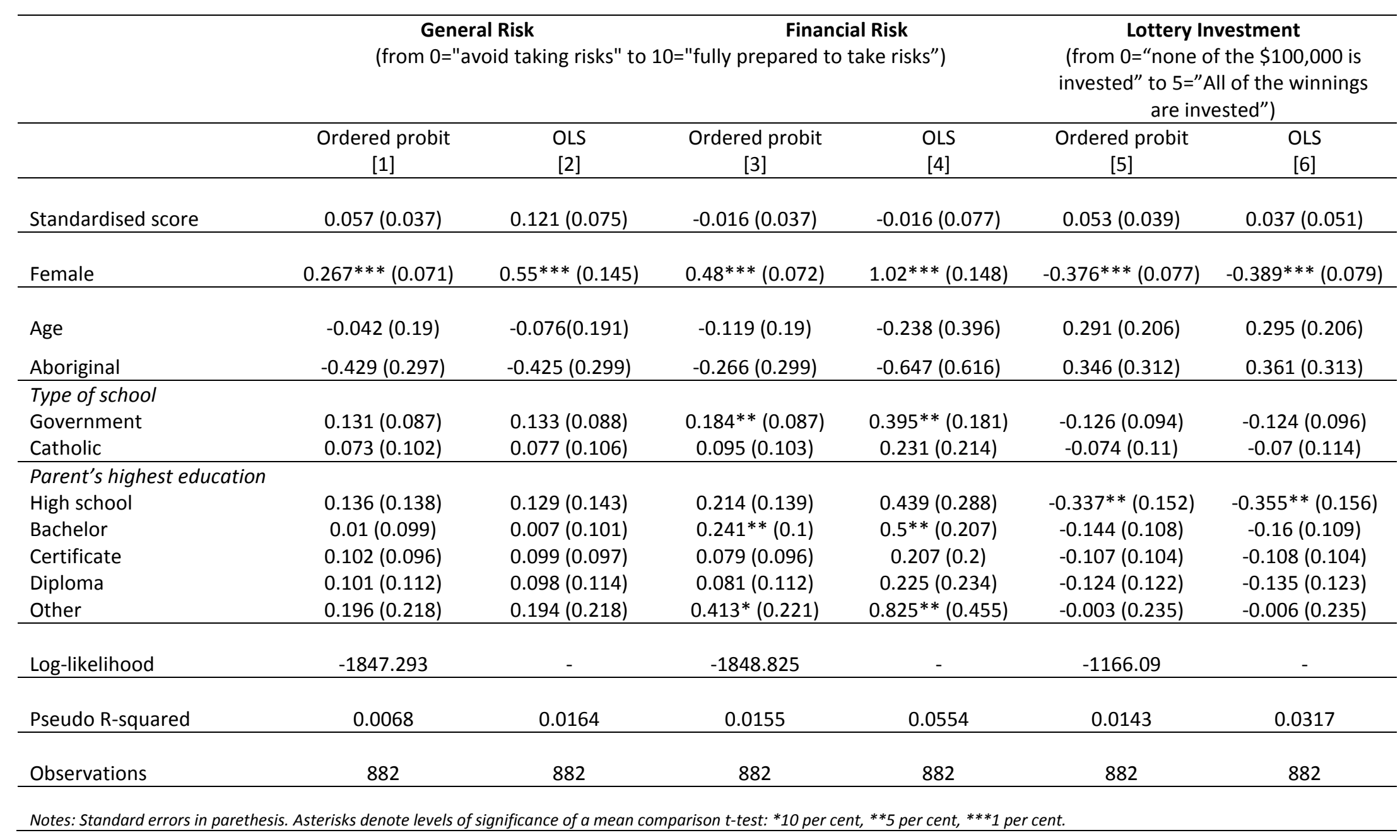

